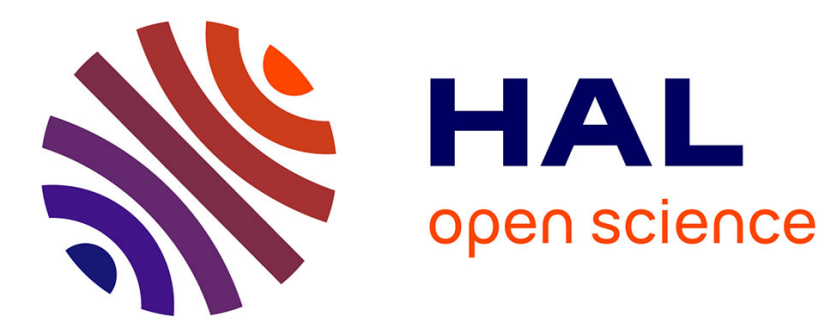

\title{
Foraging behaviour of nest predators at open-cup nests of woodland passerines
}

Karel Weidinger

\section{To cite this version:}

Karel Weidinger. Foraging behaviour of nest predators at open-cup nests of woodland passerines. Journal für Ornithologie $=$ Journal of Ornithology, 2010, 151 (3), pp.729-735. 10.1007/s10336-0100512-1 . hal-00577974

\section{HAL Id: hal-00577974 https://hal.science/hal-00577974}

Submitted on 18 Mar 2011

HAL is a multi-disciplinary open access archive for the deposit and dissemination of scientific research documents, whether they are published or not. The documents may come from teaching and research institutions in France or abroad, or from public or private research centers.
L'archive ouverte pluridisciplinaire HAL, est destinée au dépôt et à la diffusion de documents scientifiques de niveau recherche, publiés ou non, émanant des établissements d'enseignement et de recherche français ou étrangers, des laboratoires publics ou privés. 


\title{
Foraging behaviour of nest predators at open-cup nests of woodland passerines
}

\author{
Karel Weidinger
}

Received: 24 October 2009/Revised: 7 February 2010/Accepted: 1 March 2010/Published online: 18 March 2010

(C) Dt. Ornithologen-Gesellschaft e.V. 2010

\begin{abstract}
Nest predation patterns and processes cannot be understood without studying the behaviour of predators. I videotaped the behaviour of 22 species of predators at 171 depredated nests of 13 passerine species, in woodland in the Czech Republic. About 32\% (60/187) of all events occurred during the night; mammals accounted for $95 \%$ $(57 / 60)$ and $22 \%$ (28/127) of nocturnal and diurnal predation, respectively. About 67\% (57/85) of mammalian predation, but only $3 \%(3 / 102)$ of avian predation, occurred during night. Multiple predations by the same species were detected in at least $7 \%(6 / 82)$ and $42 \%$ (37/88) of nests depredated by mammals and birds, respectively. Martens Martes martes/foina took nest content mostly all at once; birds (mainly Jay Garrulus glandarius) revisited partially depredated nest during 1-4 consecutive days. Martens stayed at the depredated nest about five times longer than Jays. Martens spent similar time at nests with eggs and nestling, while Jays stayed about twice longer at nests with eggs. Mammals consumed eggs always at the nest (23/23), but took nestlings away in at least $48 \%$ (31/64) cases. Birds took the eggs and nestling away in at least $31 \%(18 / 58)$ and $76 \%$ (71/94) cases, respectively. Predator visits to active nests without taking the content, repeated partial predation
\end{abstract}

Communicated by T. Friedl.

Electronic supplementary material The online version of this article (doi:10.1007/s10336-010-0512-1) contains supplementary material, which is available to authorized users.

\section{K. Weidinger $(\square)$}

Department of Zoology and Laboratory of Ornithology,

Faculty of Science, Palacky University, Tr. Svobody 26,

77146 Olomouc, Czech Republic

e-mail: weiding@prfnw.upol.cz and revisitation of previously depredated nests suggest an effect of memory on predator's foraging behaviour.

Keywords Nest predation - Predatory behaviour . Predator-prey interactions - Activity patterns $\cdot$ Songbirds

\section{Introduction}

Nest predation patterns and processes cannot be fully understood without studying the predators themselves (Lima 2002; Thompson 2007). In spite of technical constraints, identification of nest predators became an integral part of avian nesting studies. The available data show that the relative importance of different nest predator species/ classes varies greatly in space and time (Thompson 2007; Teunissen et al. 2008; Weidinger 2009). Accordingly, variability in predation rates is often accounted for by variation in species composition of local predators. Implicit in such an explanation are predator-specific effects and avian responses to the risks imposed by particular types of predators (Caro 2005; Lima 2009). Interpretation of predator-specific effects in turn invokes some aspects of individual predator behaviour, such as habitat use, diel and seasonal activity, and nest searching methods. Foraging theory has been proposed as a useful framework to understand mechanistically the behaviour of nest predators (Schmidt 1999). However, the study of behaviour of individual nest predators is inherently difficult and only a few studies have tried to differentiate among alternative mechanisms (e.g. Schmidt et al. 2001; Vigallon and Marzluff 2005). Progress in this field is hindered, among others, by the lack of basic knowledge of predator foraging behaviour.

In spite of accumulating data on species identity of nest predators, the accounts of predator behaviour are so far 
mostly anecdotal. This is so because direct observations of nest predation acts are extremely rare (e.g. Sealy 1994), while recording the time of predation events (Rastogi et al. 2006) or still photography (O'Brien and Kinnaird 2008) cannot reveal important aspects of predatory behaviour (e.g. duration of nest visits). Even a continuous video recording of predatory behaviour has several limitations (Weidinger 2008a, 2009; Richardson et al. 2009). First of all, an insufficient spatial and temporal replication of field studies, or lack of it, implies repeated sampling of the same or a few individual predators (Sanders and Maloney 2002; Teunissen et al. 2008). Apart from being pseudoreplicated, the sample sizes available for different predator and prey species are almost always insufficient for quantitative analyses. Finally, the range of species studied so far is restricted and strongly geographically biased (Thompson 2007; Richardson et al. 2009).

A 5-year video monitoring of open-cup passerine nests in woodland habitats of the Czech Republic provided a comparatively large dataset on predator species composition (Weidinger 2009). Here, I present a descriptive account of the predators' behaviour during the documented acts of nest predation, in particular the diel activity, frequency and duration of predatory nest visits and handling of prey. Finally, I show how these data might help to explain various patterns in nest predation previously documented in this study system.

\section{Methods}

Study area and field methods

The study took place near the town Luže, the Czech Republic $\left(49^{\circ} 54^{\prime} \mathrm{N}, 16^{\circ} 02^{\prime} \mathrm{E}\right.$; altitude $\left.240-350 \mathrm{~m}\right)$, from 2002 to 2006 . The study area is characterised by a mosaic of arable land, with villages and remnants of deciduous woodland (woodlots and riparian strips; $<5 \%$ of total area). I collected data on nine plots located in distinct habitat patches (nearest-neighbour distance $1.4-3.7 \mathrm{~km}$ ) to reduce repeated sampling of the same few individual predators. The five most represented prey species in the sample of monitored nests were Blackcap Sylvia atricapilla, Song Thrush Turdus philomelos, Blackbird Turdus merula, Yellowhammer Emberiza citrinella and Chaffinch Fringilla coelebs. A full list of monitored passerine species and details of the field protocol have been described elsewhere (Weidinger 2009).

Interpretation of video records

I defined nest visit as a single continuous presence of a predator or potential predator at the nest. Nest visits were categorised as lethal (at least one egg/nestling taken) and non-lethal (nest content left undamaged) (Sanders and Maloney 2002). For each nest visit, I determined the species of the predator, timing and duration of the visit and predatory behaviour (handling of prey). I tried to determine predators to the lowest taxonomic level (see Electronic supplementary matter, ESM, Table S5, for scientific names) but I could not distinguish whether multiple nest visits by the same predator species were by the same or by different individuals. Duration of a nest visit was delimited by the times when the predator was first and last visible on the video record. Given the cameras' field of view, the visibility of predators on video records refers to their presence within c. $1 \mathrm{~m}$ around the monitored nests. Duration of complete nest depredation was defined as the time period from the first to the last lethal visit by a particular predator species, including duration of these visits.

The predation event was defined as a record of one predator species depredating one nest. If a nest was sequentially depredated by several predator species, I counted one predation event for each species. Repeated visits of the same predator species to the same nests were considered in the analysis of predator behaviour (all nest visits) and in the analysis of timing of predation (visits on different days). I categorised predation events as diurnal or nocturnal according to the timing of the first lethal visit within each day. Diurnal events were those occurring from sunrise to sunset.

Continuous videotaping produced large amounts of recorded footage but technical constraints permitted the analysis of only part of it. Specifically, when a nest was checked empty or when some eggs or nestlings were missing, I viewed video tape backwards to find the preceding event. However, the nest content was not always clearly visible on video record (e.g. camera or nest obscured by vegetation) and I checked nests visually only if parent bird was not attending the nest (to reduce disturbance). It is thus likely that an unknown proportion of video-recorded partial nest losses and non-lethal nest visits to active nests remained undetected. Consequently, the presented values for the number of visits per nest, duration of complete nest depredation and frequency of non-lethal visits represent minimum estimates. Nevertheless, all termination events (the last lethal visit to a given nest) could be safely detected. I examined recordings for $1 \mathrm{~h}$ after each termination visit; hence the estimated frequency of postpredation nest visits is restricted to this period.

\section{Dataset and analysis}

I videotaped behaviour of 22 species of predators at 171 depredated nests of 13 passerine species. Although the total sample of video records is comparatively large, the 
distribution among different predator species is heavily unbalanced. Considering only one record of a particular predator species per nest, the four dominant predators accounted for $81 \%(144 / 178)$ and mammals for $48 \%(85 /$ 178) of all predation events (Weidinger 2009). Results for the four dominant predators are shown graphically in the figures below; complete data for all predators are tabulated in ESM, Tables S1-S5. The present analysis is exploratory. I focused on describing patterns in the data; test results are shown only where they might be useful in supporting major quantitative claims. Specifically, I evaluated whether the diel distribution of predation times (all species combined) deviates from the uniform pattern (onesample Kolmogorov-Smirnov test for continuous data; $\mathrm{KS}$ ). A chi-square goodness-of-fit test (GOF; $d f=1$ ) was used to evaluate whether the frequencies of predation events observed during specific periods of day differ from those expected from the uniform diel distribution. Because nests in this study were monitored continuously, the exposure period (time at risk) was approximately constant for the entire 24-h period. Hence, the diel frequency distribution of predation events reflects the diel variation in relative predation risk. Inferences on the number and duration of predation events are based on two sample comparisons (Wilcoxon-Mann-Whitney test; MW). All reported $P$ values are exact.

\section{Results}

Diel activity of nest predators

Nests were under risk of predation at any time of day (Fig. 1; ESM, Table S1); the diel distribution of predation times did not deviate from the uniform pattern (KS, $P=0.375)$. About $32 \%(60 / 187)$ of all events occurred during the night, which accords (GOF, $P=0.590$ ) with the mean proportion of night-time during the nest monitoring period (34\% for the May-July period). Mammals accounted for $95 \%$ (57/60) of nocturnal predation and 22\% (28/ 127 ) of diurnal predation. About $67 \%$ (57/85) of mammalian predation, but only $3 \%(3 / 102)$ of avian predation, occurred during night-time. Of the diurnal predation by birds, only $5 \%(6 / 122)$ occurred within $1 \mathrm{~h}$ after sunrise and none occurred later than $1 \mathrm{~h}$ before sunset (ESM, Table S1). The observed frequency of predation by Jays did not deviate from the uniform expectation within $1 \mathrm{~h}$ after sunrise (vs next $7 \mathrm{~h}$; GOF, $P=0.813$ ), while the absence of predation within $1 \mathrm{~h}$ before sunset (vs preceding $7 \mathrm{~h}$ ) did so (GOF, $P=0.021$; Fig. 2). The only predators active at any time of day were Martens, though their predation was mainly nocturnal, with a minimum activity in the afternoon (Fig. 1). The observed predation by Martens was less

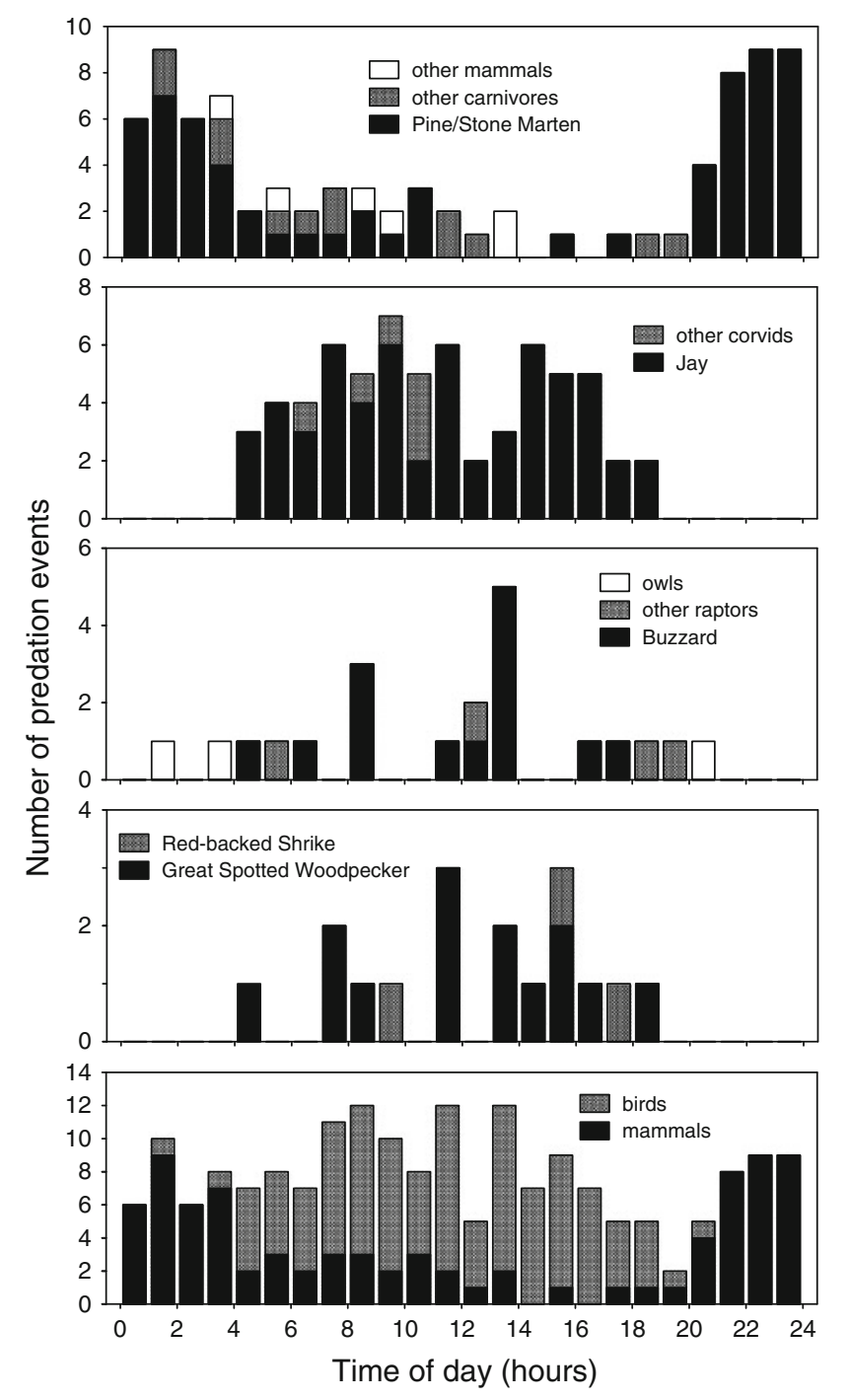

Fig. 1 Timing (in Central European Time) of predatory events on passerine nests by different species/categories of predators. Considered were all lethal visits, including repeated visits to the same nest on different days/nights (total $n=187$ ). Note different scales on the vertical axis. For a complete list of predator species and timing of the earliest/latest visits, including repeated visits during the same day/ night, see ESM, Table S1

frequent than expected within $1 \mathrm{~h}$ after sunset (vs next $3 \mathrm{~h}$; GOF, $P=0.008$ ), but did not deviate from the uniform expectation within $1 \mathrm{~h}$ before sunrise (vs preceding $3 \mathrm{~h}$; GOF, $P=0.324$; Fig. 2). Diel predation activity of Martens and Jays did not change appreciably with calendar date (Fig. 2), though the diurnal predation by Martens was recorded mainly in the middle of the nesting season.

Multi-species predation

At least 3\% (6/171) of nests were preyed upon and 5\% (8/171) of nests were visited by multiple predators - two (6 nests), three (1 nest) and four (1 nest) different predator species. The 


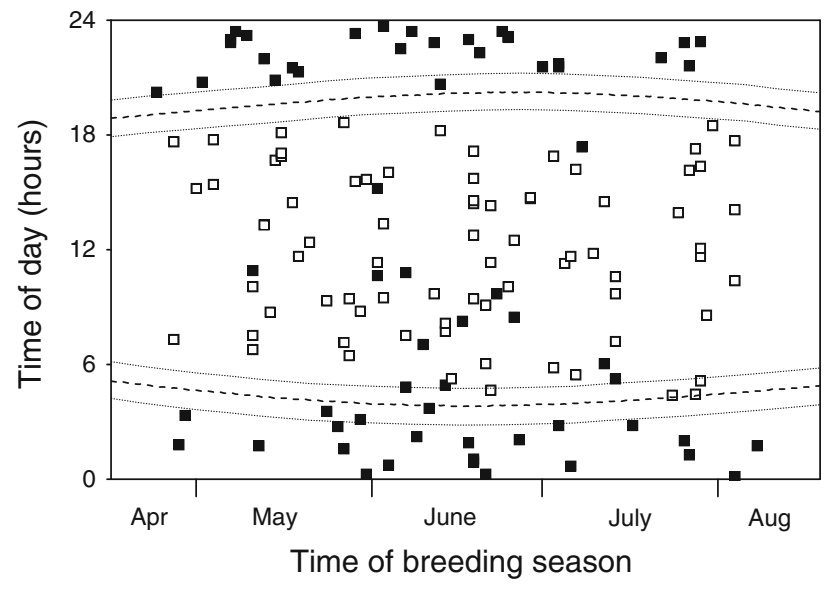

Fig. 2 Timing (in Central European Time) of predatory events on passerine nests by Martens Martes martes/foina (solid squares, $n=67$ ) and Jay Garrulus glandarius (open squares, $n=82$ ) relative to the time of sunrise and sunset (dashed lines; $\pm 1 \mathrm{~h}$ ) in course of the nesting season. Considered were all lethal visits, including repeated visits to the same nest if separated by $\geq 1 \mathrm{~h}$

shortest time intervals between the consecutive nest visits by different predators were: Jay after Squirrel $(0.27 \mathrm{~h})$, Marten after Jay (0.85 and $11.4 \mathrm{~h})$, Squirrel after Hooded Crow (1.9 h), Great Spotted Woodpecker after Jay (2.2 h), Jay after Marten (9.9 h), and Marten after Woodpecker (11.3 h).

\section{Number and duration of predatory visits}

Multiple lethal visits by the same predator species were detected in at least $7 \%(6 / 82)$ of nests depredated by mammals and $42 \%$ (37/88) of nests depredated by birds. Jays paid, on average, more visits per nest than Martens (MW, egg stage, $P=0.022$, nestling stage, $P<0.001$; Fig. 3a; ESM, Table S2). About 64\% (109/170) and 87\% (148/170) of nests were completely preyed upon during $\leq 5 \mathrm{~min}$ and $\leq 1 \mathrm{~h}$, respectively; in at least 5\% (8/170) of nests, the multiple predatory visits were distributed over more than 1 day (Fig. 3b; ESM, Table S3): Jay (2-4 consecutive days); Hooded Crow (3 days); and Buzzard and Great Spotted Woodpecker and Martens (each 2 days). Martens and Buzzard stayed at the nest on average about five times longer than Jay and Great Spotted Woodpecker (MW, Marten vs Jay, $P<0.001)$. Martens spent similar time at nests with eggs and nestling (MW, $P=0.707$ ), while Jay (MW, $P=0.003$ ) and Great Spotted Woodpecker stayed about twice as long at nests with eggs (Fig. 4; ESM, Table S4).

\section{Handling of prey}

Mammalian predators always consumed eggs at the nest (23/23), but nestlings were taken away during at least $48 \%$ (31/64) of lethal nest visits (chi-square exact test of independence in $2 \times 2$ table: $P<0.001)$. Avian predators took

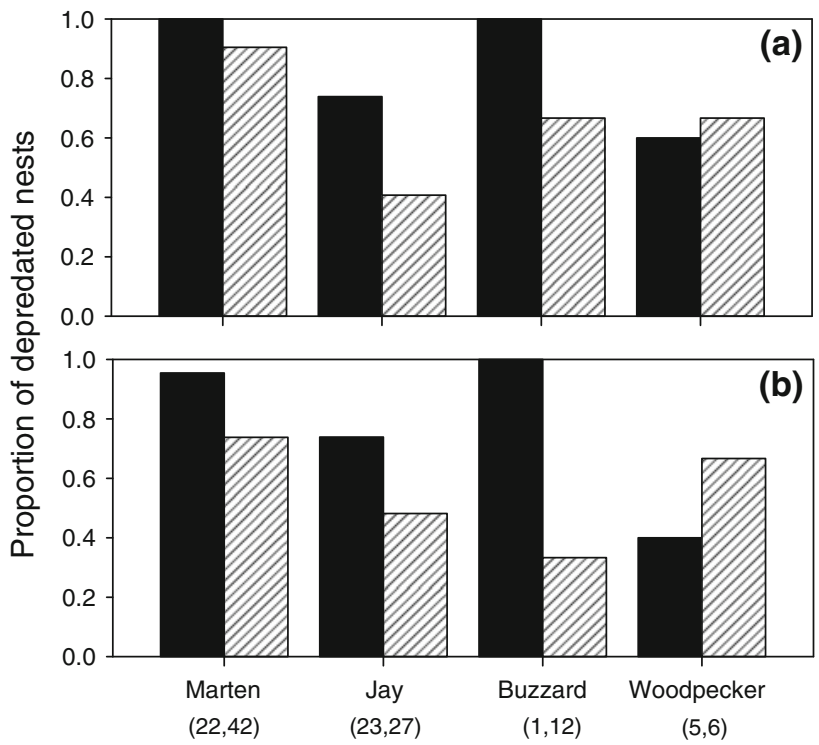

Fig. 3 Proportion of nests with eggs (solid columns) or nestlings (hatched columns) depredated. a During a single nest visit; for a complete distribution of the number of lethal visits per nest by all predator species, see ESM, Table S2. b During $\leq 5 \mathrm{~min}$, irrespective of the number of nest visits; for a complete distribution of total nest depredation times by all predator species, see ESM, Table S3. Numbers in parentheses below predator name indicate sample size for the egg and nestling stage

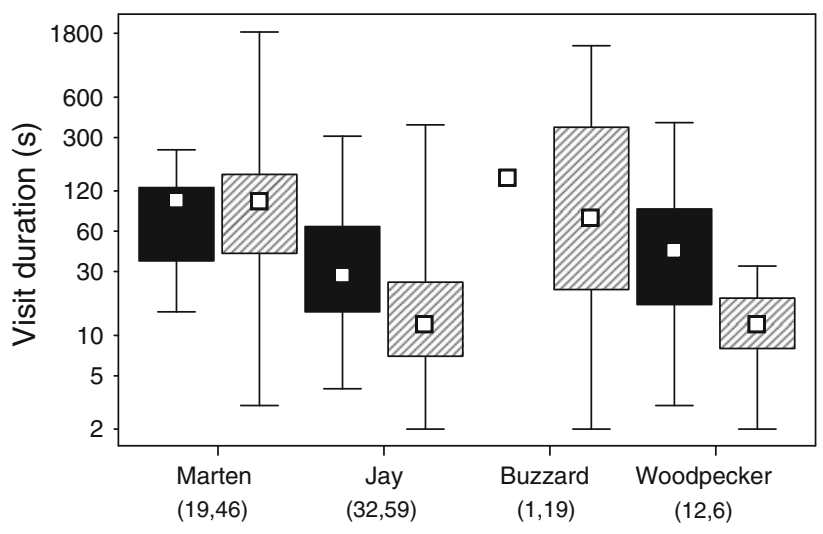

Fig. 4 Duration of one lethal visit to nest with eggs (solid boxes) or nestlings (hatched boxes) by different predators. Shown are median (square), interquartile range (box) and min-max (whiskers); note the $\log$ scale. For complete data on all predator species, see ESM, Table S4. Numbers in parentheses below predator name indicate sample size for the egg and nestling stage

eggs away during at least $31 \%(18 / 58)$ and nestlings during at least $76 \%(71 / 94)$ of lethal visits $(P<0.001)$. The only avian predator that consumed nestlings mostly (13/17) at the nest was Buzzard (Fig. 5; ESM, Table S5). Jays were seen to swallow up to two "large" Blackbird Turdus merula eggs (visit duration $45 \mathrm{~s}$ ) or four "small" Blackcap Sylvia atricapilla eggs (visit duration 19 and $20 \mathrm{~s}$, respectively) during one nest visit; nestlings were taken away always one by one. In two nests (Blackcap and 


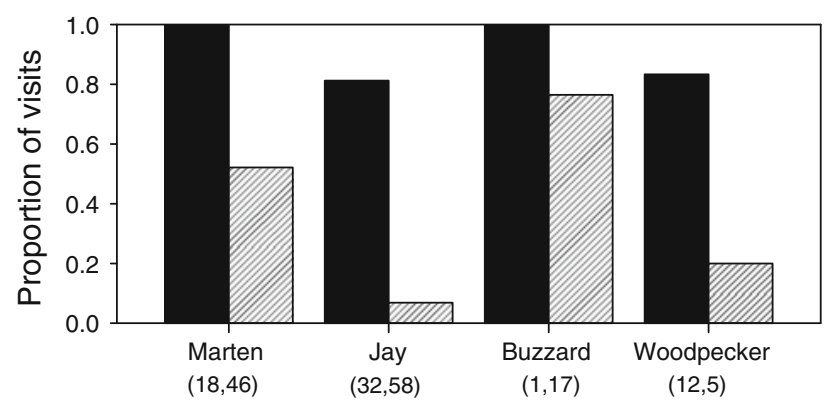

Fig. 5 Proportion of lethal nest visits during which the eggs (solid columns) or nestlings (hatched columns) were consumed directly at the nest. During the rest of visits (complement of columns to unity) the eggs or nestlings were taken away from the nest. For complete data on all predator species, see ESM, Table S5. Numbers in parentheses below predator name indicate sample size for the egg and nestling stage

Chiffchaff Phylloscopus collybita) containing young nestlings together with an unhatched egg, Jays during their last lethal visit to these nests firstly swallowed the egg and then took the remaining nestlings. Only one predation on an adult bird was firmly documented-a Long-eared Owl took (01:50) an incubating Chaffinch Fringilla coelebs, leaving the nest with eggs undamaged. Adult feathers left on and below the nest indicated another predation on incubating Song Thrush Turdus philomelos by a Marten (21:15 hours; just out of the camera field of view); Marten returned to the nest within c. $10 \mathrm{~min}$ and ate all the eggs.

Non-lethal visits by potential predators

About 6\% (11/170) of all depredated nests were revisited by the same predator species within $1 \mathrm{~h}$ after the last lethal visit: Red-backed Shrike (3/3), Domestic Cat (2/3), Weasel/ Stoat (1/6), Great Spotted Woodpecker (1/11), Buzzard (1/13), and Pine/Stone Marten (3/64). I also recorded four cases when potential predators visited nests that were eventually successful, abandoned or depredated by different predator. Firstly, an incubating Song Thrush was flushed by a Hooded Crow that thereafter pecked the nest $(1 \mathrm{~min})$ without destroying the eggs; the same behaviour was repeated after $1.5 \mathrm{~h}$. The Song Thrush continued incubation in between the two crow visits but finally deserted the intact eggs after the second crow visit. Secondly, another, probably juvenile, Hooded Crow observed $(<1 \mathrm{~min})$ an already abandoned Blackbird nest with eggs from a distance of $\mathrm{c}$ $0.5 \mathrm{~m}$. Thirdly, a Buzzard observed ( for $40 \mathrm{~s}$ ) an active Chaffinch nest with eggs (parents absent) from a distance of c. $1 \mathrm{~m}$. After 3 days of continued incubation the nest was robbed by a Jay. And, fourthly, a Pine Marten flushed an incubating Song Thrush at night (03:27 hours) and briefly (22 s) explored the nest. Incubation was not resumed, and a Pine Marten (probably the same) returned to the abandoned nest the next night and ate the eggs.

\section{Discussion}

Diel activity of nest predators

An earlier study based on a large sample of anonymous data logger records showed that nest predation in this system was distributed over the entire 24-h period, with only unclear peaks at midday and in the night (Weidinger 2008b). The present video study based on a predator-specific data supports this conclusion. The diel patterns of overall nest predation depend on the species composition of local predator community and activity of the principal predators. The almost uniform diel distribution of predatory pressure found in this study reflects an even share of the total predation by diurnal (Jay) and mainly nocturnal (Marten) species. The only comparable studies of European woodland songbirds reported either predominantly (Schaefer 2004) or exclusively (Stevens et al. 2008) diurnal predation, as most nests in these studies were depredated by Jays. Distinctly different diel patterns were reported from other systems with different principal predators: mainly nocturnal predation by carnivores on wader nests in grasslands (MacDonald and Bolton 2008; Teunissen et al. 2008) and Skylark Alauda arvensis nests in arable fields (Morris and Gilroy 2008), mainly nocturnal predation by snakes (Carter et al. 2007) or mainly diurnal predation by sciurid rodents and raptors (Liebezeit and George 2002) on arboreal nests.

The all-day predation by mammals was not only due to the occurrence of both nocturnal and diurnal species. The major predator, Martens, were active at all times of day. This contrasts with Schaefer's (2004) findings, where mammalian predation (including Martens) occurred from dusk until dawn. Predatory activity of the second dominant predator in this study, the Jay, commenced soon after sunrise and peaked around midday, which corresponds well with Schaefer's results. In spite of the comparatively large sample size, I did not record any predation by corvids later than about $1 \mathrm{~h}$ before sunset. The only detectable seasonal change was an earlier start of Jay predatory activity with advancing time of sunrise. To my knowledge, no comparable quantitative data on seasonal changes of diel activity of specific nest predators are available.

\section{Predator behaviour}

Observations that avian predators (all groups) returned to partially depredated nests while mammals (carnivores) consumed nest contents mostly in the first attempt, broadly conform to the published results on the same predator species (Schaefer 2004). Comparison with the few literature data from other biogeographical areas suggests that the general behavioural patterns, such as duration of complete nest depredation, occurrence of multi-day predation (Pietz 
and Granfors 2000; Teunissen et al. 2008), and frequency of post-predation nest visits by predators (Stake and Cimprich 2003), could be similar in various ecological contexts. The frequency of (partial) depredation of the same nest by multiple predators is seldom reported (Liebezeit and George 2003; Stake and Cimprich 2003; Small 2005; Dreibelbis et al. 2008), as it is difficult to quantify. Similarly scarce is the evidence for non-lethal visits to active nests by potential predators (Sanders and Maloney 2002; Stake and Cimprich 2003). The low frequency of such behaviours found in this and similar studies of real nests represents a minimum estimate, as not all non-termination events could be safely detected. Only a few artificial nest studies have been designed to record multiple events per nest (Leimgruber et al. 1994; Weidinger and Kočvara 2010), but those studies suggest that multiple predations by the same or by different predator species might be more common.

Implications for interpretation of nest predation patterns

The relative importance of principal predator classes is sometimes inferred from timing of predation (MacDonald and Bolton 2008). I found that mammalian predators were active both day and night and that owls also took a small share of total predation. Hence, although birds and mammals clearly prevailed during day and night, respectively, they could not be reliably distinguished solely by the timing of predation; about $17 \%$ of all events would be misclassified by the time criterion in this study. Yet, knowledge of whether predation is primarily diurnal or nocturnal might be used to assess the relative importance of visual cues to nest searching predators. For instance, parental behaviour was shown to affect vulnerability to nest predation if predators were primarily diurnal (Rastogi et al. 2006). Similarly, the lack of relationship between egg colour and overall predation rate in the present study system (Weidinger 2001) cannot be accounted for by an absence of visually oriented predators-I showed that more than half of all nest predation occurred during full daylight and most of it was attributable to predators with colour vision (birds).

Previous analysis of temporal relationships between nest predation and the timing of observer activity revealed a short-term positive observer effect that could be attributed to the deterrence of avian predators by observer presence at the monitored nests (Weidinger 2008b). Availability of species-specific data on predator activity makes it possible to check for predator-specific observer effects and to adjust field protocols of nesting studies to threats imposed by local predators. Potential for predator learning (see below) opens the possibility that predators may discover nests by observing investigators and memorizing their location, but postpone predation on them. If real, this would cause a delayed observer effect, which would be difficult to detect.
Parental nest defence is often inferred from indirect evidence (Weidinger 2002; Caro 2005), but it is inherently difficult to document directly (Pietz and Granfors 2005). The short duration of predation events by corvids and woodpeckers suggests that these relatively small/vulnerable predators minimised the time spent at the depredated nest, possibly in order to avoid being detected/attacked by the parents. In contrast, comparatively long duration of predatory events by carnivores and raptors suggests that behaviour of these large/less vulnerable predators did not seem to be influenced by the danger of parental nest defence. For instance, Buzzards regularly interrupted feeding on nest contents by periods of comfort behaviour (preening), directly on or close to the depredated nest.

From the perspective of optimal foraging theory, the generally short handling time of eggs/nestlings in open-cup passerine nests seems to be less important for the predator's foraging decisions than the time needed to discover a nest and to check its status (Schmidt 1999). Whether nest predation is mostly incidental or learned is not yet clear (Vigallon and Marzluff 2005). Predation on artificial nests in the present study system was shown to be repeatable within experimental trial ( length of nesting cycle) for all major predators, which was explained by a short-term effect of predator memory, rather than by independent multiple discoveries of the same nest (for details, see Weidinger and Kočvara 2010). In line with this, several aspects of predator behaviour at real nests as described here (revisitation of partially depredated nests, post-predation visits, non-lethal visits to active nests) suggest that predators can memorise nest locations, thus making learned nest searching possible (Sonerud and Fjeld 1987).

This study demonstrated that even simple descriptive account of predator behaviour permitted useful insights into observed nest predation patterns. Truly quantitative analyses of predator behaviour are still constrained by the currently manageable sample sizes, but development of nest surveillance technology is promising. Any future research of nest predation should consider not only the species identity of nest predators, but also aspects of their foraging behaviour.

\section{Zusammenfassung}

Nahrungserwerbsverhalten von Nesträubern an offenen Napfnestern von Wald-Sperlingsvögeln

Nestprädationsmuster und -prozesse können nicht verstanden werden, ohne das Verhalten der Räuber zu untersuchen. Ich habe das Verhalten von 22 Nesträuberarten an 171 geplünderten Nestern von 13 Sperlingsvogelarten in Waldgebieten in Tschechien auf Video aufgezeichnet. Etwa 32\% (60/187) aller Prädationsereignisse fanden in der Nacht statt; Säuger 
waren für 95\% (57/60) der nächtlichen und 22\% (28/127) der Prädationsereignisse am Tag verantwortlich. Etwa 67\% (57/ 85) der Prädation durch Säuger, jedoch nur 3\% (3/102) der Prädation durch Vögel geschahen in der Nacht. Mehrfache Prädation durch dieselbe Art wurde bei mindestens 7\% (6/82) der von Säugern und 42\% (37/88) der von Vögeln geräuberten Nester erfasst. Marder Martes martes/foina nahmen meist den gesamten Nestinhalt auf einmal; Vögel (hauptsächlich Eichelhäher Garrulus glandarius) kehrten zu teilweise geräuberten Nestern während der folgenden 1-4 Tage zurück. Marder blieben an den geräuberten Nestern etwa fünfmal so lange wie Eichelhäher. Marder hielten sich an Nestern mit Nestlingen genauso lange auf wie an Nestern mit Eiern, während Eichelhäher an Nestern mit Eiern etwa doppelt so lange blieben. Säuger fraßen Eier immer am Nest (23/23), aber nahmen Nestlinge in mindestens $48 \%(31 / 64)$ der Fälle mit. Vögel nahmen Eier in mindestens 31\% (18/58) und Nestlinge in mindestens $76 \%$ (71/94) der Fälle mit. Nesträuberbesuche an aktiven Nestern ohne Mitnahme des Inhalts, wiederholte teilweise Prädation und erneutes Besuchen zuvor geräuberter Nester deuten darauf hin, dass Erinnerung das Nahrungserwerbsverhalten von Nesträubern beeinflusst.

Acknowledgments This work was supported by the Czech Science Foundation (GAČR 206/07/0483) and by the Ministry of Education of the Czech Republic (MSM 6198959212). I would like to thank T. Koutný for help with inspection of video records and P. Adamík for comments on the manuscript. All procedures used in this study comply with the current laws of the Czech Republic.

\section{References}

Caro TM (2005) Antipredator defenses in birds and mammals. University of Chicago Press, Chicago

Carter GM, Legare ML, Breininger DR, Oddy DM (2007) Nocturnal nest predation: a potential obstacle to recovery of a Florida Scrub-Jay population. J Field Ornithol 78:390-394

Dreibelbis JZ, Melton KB, Aguirre R, Collier BA, Hardin J, Silvy NJ, Peterson MJ (2008) Predation of Rio Grande Wild Turkey nests on the Edwards Plateau, Texas. Wilson J Ornithol 120:906-910

Leimgruber P, McShea WJ, Rappole JH (1994) Predation on artificial nests in large forest blocks. J Wildl Manag 58:254-260

Liebezeit JR, George TL (2002) Nest predators, nest-site selection, and nesting success of the Dusky Flycatcher in a managed ponderosa pine forest. Condor 104:507-517

Liebezeit JR, George TL (2003) Comparison of mechanically eggtriggered cameras and time-lapse video cameras in identifying predators at dusky flycatcher nests. J Field Ornithol 74:261-269

Lima SL (2002) Putting predators back into behavioral predator-prey interactions. Trends Ecol Evol 17:70-75

Lima SL (2009) Predators and the breeding bird: behavioral and reproductive flexibility under the risk of predation. Biol Rev 84:485-513

MacDonald MA, Bolton M (2008) Predation on wader nests in Europe. Ibis 150:54-73
Morris AJ, Gilroy JJ (2008) Close to the edge: predation risks for two declining farmland passerines. Ibis 150:168-177

O'Brien TG, Kinnaird MF (2008) A picture is worth a thousand words: the application of camera trapping to the study of birds. Bird Conserv Int 18:S144-S162

Pietz PJ, Granfors DA (2000) Identifying predators and fates of grassland passerine nests using miniature video cameras. J Wildl Manag 64:71-87

Pietz PJ, Granfors DA (2005) Parental nest defence on videotape: more reality than "myth". Auk 122:701-705

Rastogi AD, Zanette L, Clinchy M (2006) Food availability affects diurnal nest predation and adult antipredator behaviour in song sparrows, Melospiza melodia. Anim Behav 72:933-940

Richardson TW, Gardali T, Jenkins SH (2009) Review and metaanalysis of camera effects on avian nest success. J Wildl Manag 73:287-293

Sanders MD, Maloney RF (2002) Causes of mortality at nests of ground-nesting birds in the Upper Waitaki Basin, South Island, New Zealand: a 5-year video study. Biol Conserv 106:225-236

Schaefer T (2004) Video monitoring of shrub-nests reveals nest predators. Bird Study 51:170-177

Schmidt KA (1999) Foraging theory as a conceptual framework for studying nest predation. Oikos 85:151-160

Schmidt KA, Goheen JR, Naumann R (2001) Incidental nest predation in songbirds: behavioral indicators detect ecological scales and processes. Ecology 82:2937-2947

Sealy SG (1994) Observed acts of egg destruction, egg removal, and predation on nests of passerine birds at Delta Marsh, Manitoba. Can Field-Nat 108:41-51

Small SL (2005) Mortality factors and predators of spotted towhee nests in the Sacramento Valley, California. J Field Ornithol 76:252-258

Sonerud GA, Fjeld PE (1987) Long-term memory in egg predators: an experiment with a hooded crow. Ornis Scand 18:323-325

Stake MM, Cimprich DA (2003) Using video to monitor predation at black-capped vireo nests. Condor 105:348-357

Stevens DK, Anderson GQA, Grice PV, Norris K, Butcher N (2008) Predators of spotted flycatcher Muscicapa striata nests in southern England as determined by digital nest cameras. Bird Study 55:179-187

Teunissen W, Schekkerman H, Willems F, Majoor F (2008) Identifying predators of eggs and chicks of lapwing Vanellus vanellus and black-tailed godwit Limosa limosa in the Netherlands and the importance of predation on wader reproductive output. Ibis 150:74-85

Thompson FR (2007) Factors affecting nest predation on forest songbirds in North America. Ibis 149:98-109

Vigallon SM, Marzluff JM (2005) Is nest predation by Steller's jays (Cyanocitta stelleri) incidental or the result of a specialized search strategy? Auk 122:36-49

Weidinger K (2001) Does egg colour affect predation rate on open passerine nests? Behav Ecol Sociobiol 49:456-464

Weidinger K (2002) Interactive effects of concealment, parental behaviour and predators on the survival of open passerine nests. J Anim Ecol 71:424-437

Weidinger K (2008a) Identification of nest predators: a sampling perspective. J Avian Biol 39:640-646

Weidinger K (2008b) Nest monitoring does not increase nest predation in open-nesting songbirds: inference from continuous nest-survival data. Auk 125:859-868

Weidinger K (2009) Nest predators of woodland open-nesting songbirds in central Europe. Ibis 151:352-360

Weidinger K, Kočvara R (2010) Repeatability of nest predation in passerines depends on predator species and time scale. Oikos 119:138-146 